\title{
CIRCULATING BACTERIAL LIPOPOLYSACCHARIDE-INDUCED INFLAMMATION REDUCES FLOW IN BRAIN-IRRIGATING ARTERIES INDEPENDENTLY FROM CEREBROVASCULAR PROSTAGLANDIN PRODUCTION
}

\author{
FRÉDÉRIC VILLÉGA, ${ }^{\mathrm{a}, \mathrm{b} \dagger}$ \\ JEAN-CHRISTOPHE DELPECH, ${ }^{\mathrm{c}, \mathrm{d} \dagger}$ MARION GRITON, ${ }^{\mathrm{b}, \mathrm{c}, \mathrm{e}}$ \\ CAROLINE ANDRÉ, c,d JEAN-MICHEL FRANCONI, \\ SYLVAIN MIRAUX ${ }^{\mathrm{b}, \mathrm{c}}$ AND JAN PIETER KONSMAN ${ }^{\mathrm{b}, \mathrm{C*}}$ \\ ${ }^{a}$ Service de Neuropédiatrie, CIC-0005, Centre Hospitalier \\ Universitaire (CHU) de Bordeaux, Bordeaux, France \\ ${ }^{\mathrm{b}}$ CNRS, Résonance Magnétique des Systèmes Biologiques, \\ UMR 5536, Bordeaux, France \\ ${ }^{\mathrm{C}}$ Univ. Bordeaux, RMSB, UMR 5536, Bordeaux, France \\ ${ }^{\mathrm{d}}$ CNRS, PsychoNeurolmmunologie, Nutrition et Génétique, \\ UMR 5226, Bordeaux, France \\ e Service de Anesthésie Réanimation Neurochirurgicale, \\ Centre Hospitalier Universitaire (CHU) de Bordeaux, \\ Bordeaux, France
}

\begin{abstract}
Brain dysfunction is a frequent complication of the systemic inflammatory response to bacterial infection or sepsis. In the present work, the effects of intravenous bacterial lipopolysaccharide (LPS) administration on cerebral arterial blood flow were assessed with time-of-flight (TOF)-based magnetic resonance angiography (MRA) in mice. Cerebral expression of the transcription factors nuclear factor-kappaB (NF-kB) and c-Fos and that of enzymes synthesizing vasoactive mediators, such as prostaglandins and nitric oxide, known to be increased under inflammatory conditions, were studied in the same animals. Time-resolved TOF MRA revealed no differences in blood flow in the internal carotids upstream of the circle of Willis, but indicated lower flow in its lateral parts as well as in the middle and anterior cerebral arteries after intravenous LPS injection as compared to saline administration. Although LPS did not increase c-Fos expression in ventral forebrain structures of these animals, it did induce NF-kB in
\end{abstract}

\footnotetext{
${ }^{*}$ Correspondence to: J. P. Konsman, CNRS UMR 5536, Résonance Magnétique des Systèmes Biologiques, Université de Bordeaux, 146 rue Léo Saignat, 33076 Bordeaux Cedex, France. Fax: + 33-5-57-5745-56.

E-mail address: jan-pieter.konsman@u-bordeaux.fr (J. P. Konsman).

$\dagger$ Contributed equally to this work.

Abbreviations: ACA, anterior cerebral artery; ANOVA, analysis of variance; AUC, area under the curve; COX-2, cyclooxygenase-2; ET-1, endothelin-1; I, interval; iNOS, inducible nitric oxide synthase; iv, intravenous; LPS, lipopolysaccharide; MCA, middle cerebral artery; MCP-1/CCL2, monocyte chemoattractant protein-1; mPGES, microsomal prostaglandin $E$ synthase; MRA, magnetic resonance angiography; NF-кB, nuclear factor-kappaB; PBS, phosphate-buffered saline; PCR, polymerase chain reaction; $\mathrm{PVH}$, paraventricular nucleus of the hypothalamus; REST, Relative Expression Software Tool; ROI, region of interest; TNF $\alpha$, tumor necrosis factor-alpha; TOF, time-offlight; UV, ultraviolet.
}

meningeal blood vessels. LPS also increased cerebral expression of cyclooxygenase-2 and prostaglandin E synthase mRNAs, but de novo expression occurred in veins rather than in arteries. In conclusion, our work indicates that LPS-induced systemic inflammation does not necessarily affect filling of the circle of the Willis from the periphery, but that circulating LPS alters outflow from the circle of Willis to the middle and anterior cerebral arteries. These modifications in arterial flow were not related to increased cerebral synthesis of prostaglandins, but may instead be the consequence of the action of circulating prostaglandins and other vasoactive mediators on brain-irrigating arteries during systemic inflammation. (c) 2017 IBRO. Published by Elsevier Ltd. All rights reserved.

Key words: angiography, anterior cerebral artery, cerebral blood flow, encephalopathy, prostaglandin, sepsis.

\section{INTRODUCTION}

Sepsis has long been recognized to be associated with nervous system dysfunction (Levy et al., 2003; Baron et al., 2006). Indeed, altered mental status is present in about a quarter of sepsis patients (Sprung et al., 1990) and can even occur before other signs (Ebersoldt et al., 2007). Moreover, sepsis-associated encephalopathy, for diffuse or multifocal cerebral dysfunction, ranging from lethargy to coma, is present in $70 \%$ of patients with bacteremia (Wilson and Young, 2003). Finally, severe sepsis survivors often develop long-term cognitive impairments and behavioral problems and experience a reduction in quality of life comparable to that seen after a heart attack (Heyland et al., 2000; Iwashyna et al., 2010; Lazosky et al., 2010; Pandharipande et al., 2013).

Given that the brain is highly dependent on blood supply to function properly (Rolfe and Brown, 1997) and that sepsis comes with a high risk of organ hypoperfusion (Jones and Puskarich, 2009), it is likely that sepsisassociated encephalopathy is related to reduced cerebral blood flow. Septic patients with encephalopathy do indeed show a reduction in global cerebral blood flow compared to healthy controls (Bowton et al., 1989; Maekawa et al., 1991). Interestingly, this finding can be reproduced by intravenous administration of bacterial lipopolysaccharides (LPS) in human volunteers (Moller et al., 2002). However, the techniques used in these initial studies did 
not allow for determination where the reduction in flow occurred in the cerebral blood supply. More recent clinical studies have applied time-of-flight (TOF) magnetic resonance angiography (MRA) to sepsis-associated encephalopathy and shown anatomical signs of vasospasms in branches of the anterior and middle cerebral arteries (ACA and MCA) (Bartynski et al., 2006; Polito et al., 2013). In addition, flow speed in the territory of the MCA, as measured with transcranial Doppler, has been shown to be reduced after iv LPS administration in healthy volunteers (Brassard et al., 2012). These findings indicate that vasoconstrictive mechanisms in brainsupplying arteries may reduce cerebral blood flow during sepsis.

In the present work, we set out to better understand sepsis-associated changes in cerebral arterial bloodsupply by trying to model these in animals. Timeresolved 3D TOF MRA was used to functionally characterize the high-flow systems of the circle of Willis, ACA and MCA during systemic inflammation after intravenous administration of bacterial LPS in mice. In animals, prostaglandins, nitric oxide and endothelin-1 (ET-1) have been shown to be vasoactive molecules in brain arteries and arterioles (Toda et al., 1988; Faraci and Brian, 1994; Salom et al., 1995; Davidge, 2001; Jadhav et al., 2004; Dabertrand et al., 2013). Interestingly, in vitro rodent cerebral arteries rapidly respond to LPS by increasing the expression of cyclooxygenase-2 (COX-2), the rate-limiting enzyme in prostaglandin synthesis (Hernanz et al., 2004). Moreover, systemic administration of bacterial LPS or pro-inflammatory cytokines increases cerebral expression of the prostaglandinsynthesizing enzymes COX-2 and microsomal prostaglandin E synthase (mPGES) as well as that of inducible nitric oxide synthase (iNOS) and ET-1 in rodents (Wong et al., 1996; Elmquist et al., 1997; Konsman et al., 1999, 2004; Ek et al., 2001; Yamagata et al., 2001; Shimojo et al., 2006; Eskilsson et al., 2014). Since increased expression of these molecules involves nuclear factor-kappaB (NF-кB) (D'Acquisto et al., 1997; Abate et al., 1998; Zhao et al., 2001; Wort et al., 2009), we set out to study expression of this transcription factor in addition to that of the more general cellular activation marker c-Fos, COX-2, mPGES, iNOS and ET-1 in the brains of animals that underwent MRA as a first approach to determine potential mechanisms underlying sepsis-related changes in cerebral blood flow.

\section{EXPERIMENTAL PROCEDURES}

\section{Animals}

Experiments were conducted according to European recommendations on animal research (European Council Directive of 24 November 1986 (86/609/EEC) and European Parliament and Council Directive of 22 September 2010 (2010/63/UE)) and approved by the local committee for animal experimentation (AS-SNCDEV Dir1434). After arrival, 20 male 3- month-old C57/ BI6 (Charles River, Arbresle, France) were allowed at least one week of acclimation in group cages with ad libitum access to food and water in a temperature $\left(22^{\circ} \mathrm{C} \pm 1^{\circ} \mathrm{C}\right)$-controlled environment where lights were on from $08: 00$ to $20: 00 \mathrm{~h}$.

\section{Magnetic resonance imaging}

On the day of experiment, mice were removed from their cage, anesthetized with $1.5-2.0 \%$ isoflurane and an intravenous catheter placed into their caudal tail vein. This catheter was connected to a syringe containing either LPS or saline. Under continued anesthesia, mice were then placed in a 4.7 $\mathrm{T}$ horizontal magnet (Bruker, Ettlingen, Germany) equipped with a 6-cm BG6 gradient system capable of generating $950 \mathrm{mT} / \mathrm{m}$ maximum strength and an $80-\mu$ s rise time. During imaging, respiratory rate was monitored and maintained between 80 and 100 breaths per minute and body temperature sustained by warm water circulating in the machine's gradients.

\section{Time-resolved 3D MRA}

Blood flow in internal carotids, the circle of Willis and the first segments of the ACA and MCA was assessed using a slightly modified bright blood time-resolved 3D MRA sequence previously developed and validated for the mouse carotid system (Miraux et al., 2006). It covered filling of the circle of Willis and the ACA and MCA by arterial blood in 8 images spanning $64 \mathrm{~ms}$ with a field of view of $2.0 \times 1.6 \times 1.4 \mathrm{~cm}$ and a matrix of $128 \times 80 \times 48$ voxels, thus yielding a spatial resolution of $156 \times 200 \times 292 \mu \mathrm{m}$. The sequence was applied once before intravenous injection and repeated 6 times over time thereafter. Subtraction operations between the images covering $64 \mathrm{~ms}$ were performed in IGOR Pro 6.04 (Wavemetrics, Lake Oswego, OR, USA) to yield the number of voxels that have appeared in a given interval as a measure of the blood volume that has filled different arterial segments over time. After application of a fixed intensity threshold, the values obtained in the subtracted images after intravenous injection were divided by those measured in equivalent subtracted and thresholded images of the same animal before treatment (baseline). Thus, timeresolved 3D MRA assesses flow during a "time interval of interest" rather than in a "region of interest", even though one can determine a posteriori which arterial segments were filled during the interval in question.

\section{D MRA}

In addition to time-resolved 3D MRA to assess flow in the circle of Willis as well as in the ACA and MCA, a 3D MRA sequence on coronal slices with a field of view of $2.0 \times 1.6 \times 1.4 \mathrm{~cm}$ and a matrix of $128 \times 96 \times 64$ voxels, thus yielding a spatial resolution of $156 \times 167 \times 219 \mu \mathrm{m}$, was used to estimate flow in the internal carotids, ACA and MCA as well as in some of its major branches. This MRA sequence was alternated with time-resolved 3D MRA, applied once before intravenous injection and repeated 7 times over time thereafter. The coronal orientation was chosen to maximize the axial "entrance effect" of fresh blood as the direction of flow in the arteries of interest is often 
horizontal. The bright appearance of blood allowed for identification of a fixed internal reference position slice. Regions of interests (ROIs) centered on the internal carotid arteries, ACA, MCA, pericallosal azygos artery and anterior amygdaloid arteries were then placed on more anterior or posterior slices relative to the reference slice. Sizes of these ROls varied from 4 voxels for the smallest artery, the pericallosal azygos artery, to 9-10 voxels for the largest arteries, the internal carotids. The mean intensity of voxels in each artery was measured in Image $\mathrm{J}$ (http://rsbweb.nih.gov/ij/) and expressed relative to the mean intensity to a ROI of the same form and surface placed in a corner of the same image but outside the head (background). The resulting blood flow proxies after intravenous injection were expressed relative to that in the same ROIs of the same animal before treatment (baseline). Thus, this 3D MRA sequence allows for a "region of interest" approach, but at the expense of being able to compare different "time intervals of interest" to assess blood flow, even though the intensity of gray levels contains this information to some extent. As such it is comparable to the MRA sequences routinely used in the clinic and complementary to the time-resolved 3D MRA described above and with which it was alternated.

\section{Treatment}

Once baseline MRAs were completed, $37.5 \mu \mathrm{g}(1.25 \mathrm{mg} /$ $\mathrm{kg}$ ) of Escherichia coli LPS (Serotype 0127:B8, Sigma, St Louis, MO, USA) dissolved in $150 \mu \mathrm{l}$ of $0.9 \% \mathrm{NaCl}$ or an equivalent volume of $0.9 \% \mathrm{NaCl}$ vehicle was injected intravenously (iv) over one minute. This dose of LPS is more than ten times lower than the one needed to induce $50 \%$ mortality within $72 \mathrm{~h}$ when given by the same route (Eskandari et al., 1992). Indeed, $50 \mu \mathrm{g}$ of the same serotype of LPS injected intravenously does not result in any mortality until $40 \mathrm{~h}$ after injection, but does induce increases in circulating concentrations of pro-inflammatory cytokines and apoptosis in gut epithelium (Blank et al., 1997).

\section{Tissue preparation}

Two and a half hours after injection, and upon completion of the last MRA sequence, animals were removed from the magnet and injected with sodium pentobarbital $(0.3 \mathrm{ml}$ of $550 \mathrm{mg} / \mathrm{ml})$ while still under isoflurane anesthesia. Once the hind paw reflex upon plantar pinching had disappeared, the thoracic cage was opened to allow for placement of a needle into the left cardiac ventricle after the right atrium was cut. The circulatory system of animals was next rinsed with phosphate-buffered saline (PBS) after which brains of that half of the animals allocated to polymerase chain reaction $(P C R)$ experiments were removed within two minutes, frozen on crushed dry ice and stocked at $-80{ }^{\circ} \mathrm{C}$ while the remaining mice assigned to immunohistochemical analyses were perfused with $4 \%$ paraformaldehyde in 0.1 M PBS. After removal of these perfusion-fixed brains, they were post-fixed for $4 \mathrm{~h}$, cryoprotected in $30 \%$ sucrose, frozen on dry ice and stocked at $-80^{\circ} \mathrm{C}$.

\section{Real-time PCR}

After RNA was extracted and reverse transcribed to cDNA, real-time SYBR green-based comparative PCR was performed using a previously established protocol and set of primers (Pourtau et al., 2014). Expression of mRNA coding for COX2, mPGES, iNOS and preproET-1 relative to that of beta-actin was calculated as $2_{\mathrm{T}}^{-\Delta \mathrm{C}}$ (Schmittgen and Livak, 2008) and as fold change (Pfaffl et al., 2002). Relative expressions of monocyte chemoattractant protein1 (MCP-1)/CCL2 and tumor necrosis factor- $\alpha$ (TNF $\alpha$ ) were used as positive controls.

\section{Immunohistochemistry}

Brains were cut on a cryostat into $30-\mu \mathrm{m}$-thick sections that were collected in cold cryoprotectant $(0.05 \mathrm{M}$ phosphate buffer, $20 \%$ glycerol and $30 \%$ ethylene glycol) and stored at $-20^{\circ} \mathrm{C}$ until further processing. After washing off the cryoprotectant solution, immunohistochemical processing was performed on a one in six series of free-floating sections using the strepta vidin-biotin-immunoperoxidase technique (Konsman and Blomqvist, 2005). Briefly, non-specific binding sites were blocked by a 1-h incubation of sections in PBS, $\mathrm{pH} 7.4$, containing $0.3 \%$ Triton $\mathrm{X}-100$ and $1.0 \%$ bovine albumin. $A$ rabbit antiserum recognizing the transcription factor c-Fos (Sc-52, Santa Cruz Biotechnology, Heidelberg, Germany; diluted 1:2000), amply characterized in the past including by us (Konsman and Blomqvist, 2005; Konsman et al., 2008), was used to study neuronal activation. A goat antiserum directed against the p65 subunit of NF-кB (Sc-372, Santa Cruz Biotechnology, Heidelberg, Germany; diluted 1:500), characterized previously (Nadjar et al., 2003) was employed to assess proinflammatory signaling. A goat antiserum recognizing COX-2 (Sc-1747, Santa Cruz Biotechnology, Heidelberg, Germany; diluted 1:500), employed by our team in the past (Konsman et al., 2004) was utilized to identify cerebral sites of prostaglandin synthesis. Moreover, the c-Fos, COX-2 and NF-kappa-B antisera used in the present work are part of the Journal of Comparative Neurology antibody database that contains collected information on the antibodies used for immunohistochemistry based on that journal's policy requiring rigorous characterization for antibodies. A rabbit antiserum specific for nitrosylated tyrosine residues (nitrotyrosine; Millipore, Fontenay sous Bois, France, diluted 1:250) was used as readout for the production of $\mathrm{NO}$ and peroxynitrite during inflammation. Antisera were added at dilutions indicated to PBS, $0.3 \%$ Triton $\mathrm{X}-100$ and $1.0 \%$ bovine albumin. Sections were incubated in antiserum-containing buffers overnight at room temperature. After four rinses in PBS, sections were treated for $30 \mathrm{~min}$ in $0.3 \%(\mathrm{v} / \mathrm{v})$ hydrogen peroxide to block endogenous peroxidases followed by rinses in PBS. Sections were incubated for $2 \mathrm{~h}$ at room temperature with either biotinylated donkey anti-rabbit IgG (Amersham, Les Ulis, France) or biotinylated rabbit anti-goat IgG (Dako, Les Ulis, France) diluted 1:500 in PBS 
containing $0.3 \%$ Triton $\mathrm{X}-100$ and $1.0 \%$ bovine albumin and stained using the ABC protocol (Vectastain Elite, Vector Laboratories, Eurobio/Abcys, Les Ullis, France) with nickel-enhanced diaminobenzidine as a chromagen.

Stained sections were observed on a microscope (Leica DM5500B, Leica Microsystems, Wetzlar, Germany) under bright field illumination and images were captured by a high-resolution CCD video camera image and stored on a personal computer. Image editing software (Adobe Photoshop, Adobe Systems, San Jose, CA, USA) was used to adjust contrast and brightness only and to prepare microphotographs. Sections were also examined under ultraviolet (UV) light to distinguish between arteries and other vessel types. Indeed, excitation in the UV range provokes an autofluorescence of elastin in the wall of arteries, whereas veins are less autofluorescent due to a reduced amount of elastin (Kingsley et al., 2001; Hernanz et al., 2004).

\section{Data presentation and analysis}

MRA data were expressed as means \pm standard error of the mean (SEM) of change relative to baseline over time after injection. These data were analyzed both as area under the curve (AUC) by Student- $t$ tests with iv treatment as a between factor and by analyses of variance (ANOVA) with iv treatment as a between factor and post-injection time as a within factor. Significant effects and interactions were further analyzed by the Newman-Keuls post hoc test. The number of c-Fosimmunoreactive cells was determined in at least two sections of the ventromedial preoptic area, supraoptic and paraventricular nuclei of the hypothalamus in each animal and analyzed by a Mann-Whiney $U$ test. Realtime PCR data were expressed as $2_{\mathrm{T}}^{-\Delta \mathrm{C}}$ and analyzed by a one-way ANOVA (Schmittgen and Livak, 2008). In case a significant difference was found, data were expressed as fold change and analyzed using Pair-Wise Fixed Reallocation Randomization Tests, which take into account real amplification efficiencies (Pfaffl et al., 2002). In all cases, a level of $p<0.05$ was considered as statistically significant.

\section{RESULTS}

\section{Iv LPS resulted in lower cerebral blood flow in the} circle of Willis and in the anterior cerebral arteries

3D time-resolved MRA. An example of time-resolved 3D MRA represented by sequential maximum intensity projections and indicating the different time intervals (I1-7) is shown in Fig. 1A. The time-resolved 3D MRA sequence used here previously has been used to determine blood flow velocity in the mouse carotids to be $\sim 25 \mathrm{~cm} / \mathrm{s}$ (Miraux et al., 2006). For comparative purposes, the fronts of bright blood voxels were determined at 8,16 and $24 \mathrm{~ms}$ on the maximum intensity projection flatmaps, as these correspond to filling of the internal carotids during 11 and 12 , which occurred in an almost straight line in an approximately horizontal plane, to estimate flow. As 19 voxels had appeared during the progression of the anterior front of filling of the internal carotids between 8 and $24 \mathrm{~ms}$ along the $z$-axis, corresponding to $19 \times 0.219 \mathrm{~mm}$ (voxel size of $219 \mu \mathrm{m}$ in $z$ taking into consideration voxel spatial resolution and the field of view) $=4.2 \mathrm{~mm}$, this calculation yielded an estimate of $26.25 \mathrm{~cm} / \mathrm{s}$ flow velocity for the internal carotids, which is compatible with the values determined for the mouse carotids in our previous work (Miraux et al., 2006).

The Student- $t$ tests on AUC of data expressed as changes relative to baseline showed no differences in arterial flow between treatments during 11 and 12 , which corresponded to filling of the internal carotids and basilar artery. However, the same analyses revealed tendencies for lower flow during 13 corresponding to filling of the circle of Willis formed by the continuation of the internal carotids and the posterior communicating artery $\left(t_{1,14}=1.98, p=0.067\right)$ as well as during 14 all through which the anterior and middle cerebral arteries were filled $\left(t_{1,14}=1.92, p=0.074\right)$ in mice that were given LPS as compared to those that received its vehicle.

Since blood flow may increase with time of isoflurane anesthesia (Sicard et al., 2003; Duong, 2007; Shin et al., 2007 ), the relative number of voxels that appeared between sequential images of the filling of the circle of Willis were also analyzed by repeated-measures ANOVAs. These analyses indicated indeed significantly increased flow over time after iv injection $\left(F_{5,65}=2.52\right.$ : $p<0.05$ ), but no effect of treatment during 11 (Fig. $1 \mathrm{~A}$ ), that is during filling of the internal carotids upstream of the circle of Willis and that of the basilar artery. With respect to I3 (Fig. 1A) corresponding to filling of the lateral parts of the circle of Willis, flow also increased significantly with time of the experiment $\left(F_{5,60}=4.05\right.$ : $p<0.01)$. However, iv LPS treatment tended to result in lower flow in these vessels as compared to iv administration of saline $\left(F_{1,12}=4.34, p=0.059\right.$; Fig. $\left.1 \mathrm{~B}\right)$. Since a significant interaction occurred between time and treatment for filling of these segments $\left(F_{5,60}=2.43\right.$ : $p<0.05)$, post hoc tests were performed. These indicated that flow was significantly lower 80 min after iv LPS injection as compared to administration of its vehicle (LPS < Sal; $p<0.05$; Fig. 1B). Analysis of flow during 14 (Fig. 1A), which corresponded to filling of the initial segments of the anterior and middle cerebral arteries (ACA and $\mathrm{MCA}$ ), showed that, in addition to the increase over time $\left(F_{5,65}=4.02: p<0.01\right)$, flow was lower in mice that received iv LPS than in animals that were given saline iv $\left(F_{1,13}=8.06, p<0.05\right.$; Fig. $\left.1 \mathrm{C}\right)$.

3D MRA. Given that iv LPS compared to iv saline administration resulted in lower flow during the interval corresponding to the filling of the first segments of the ACA and MCA, blood flow in ROls placed on these arteries as well as on some of their up- and downstream arteries were assessed using 3D MRA in coronallyoriented virtual brain slices (Fig. 2A). The Student- $t$ tests on AUC of data expressed as changes relative to baseline showed lower flow in the right ACA $\left(t_{1,15}=2.47, \quad p<0.05\right)$ and the azygos pericallosal artery $\left(t_{1,15}=3.12, p<0.01\right)$ as well as a tendency for 
A

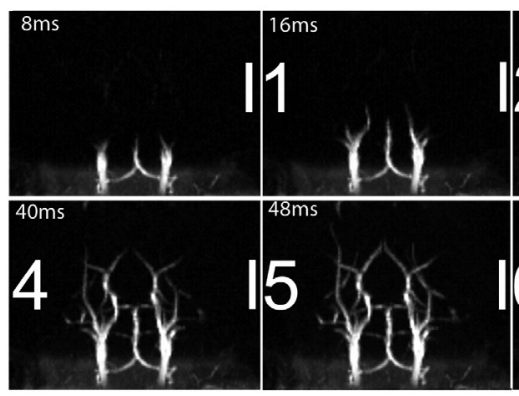

B

Posterior and lateral circle of Willis

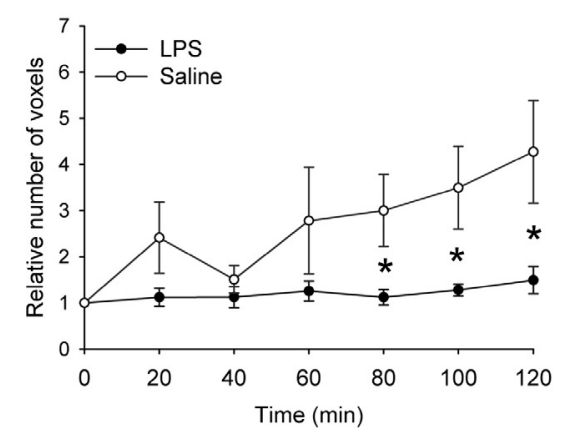

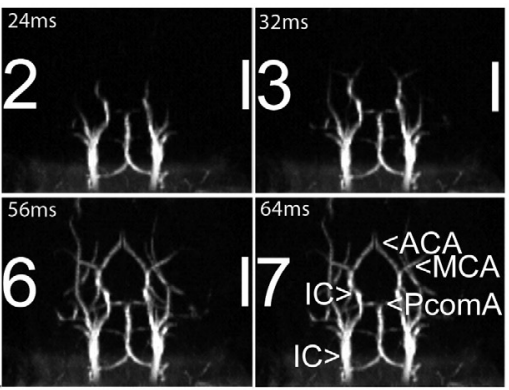

C Anterior and middle cerebral arteries

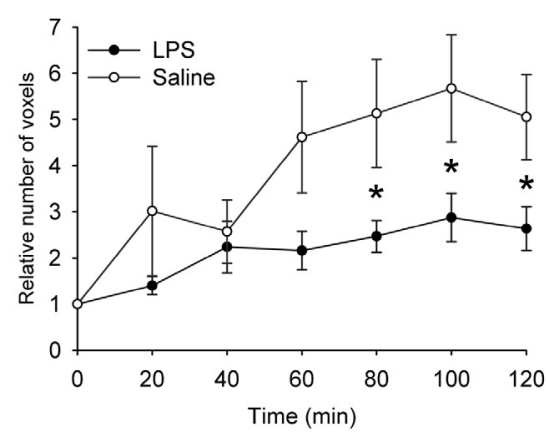

Fig. 1. Flow measurements in the mouse internal carotid arteries, circle of Willis, ACA and MCA with time-resolved 3D TOF-MRA. The top part illustrates the filling of these different arterial segments over time by a maximum intensity projection of signal in the horizontal plane $(A)$. The relative number of voxels to have appeared during intervals I3 (B: $24-32 \mathrm{~ms}$ ) and I4 (C: $32-40 \mathrm{~ms}$ ) at different time points after iv LPS or saline injection are shown in graphs. 11-7: intervals between sequential images. ACA: anterior cerebral artery, IC: internal carotid (upstream of and as part of the circle of Willis), MCA: middle cerebral artery, PcomA: posterior communicating artery. ${ }^{*} p<0.05$. Group sizes Sal: $n=9-10$; LPS: $n=9-10$.

lower flow in the left ACA $\left(t_{1,15}=1.96, p=0.069\right)$ in mice that were injected with LPS as compared to those that were administered saline.

Since blood flow may increase with time of isoflurane anesthesia (Sicard et al., 2003; Duong, 2007; Shin et al., 2007), flow data obtained in ROls placed on arteries were also analyzed by repeated-measures ANOVAs. ANOVAs with treatment as a between factor and time after injection as a within subject factor indicated that blood flow was lower in ROls placed on the ACAs at the base of the brain after iv LPS injection than after iv saline administration $\left(F_{1,15}=6.08, p<0.05\right.$ and $F_{1,15}=4.91, p<0.05$ for the right and left $A C A$, respectively; Fig. $2 C$ ), whereas flow in the internal carotids upstream of the circle of Willis (Fig. 2B) and in the MCAs was not different between treatments, but did increase over time $\left(F_{6,90}=3.20, p<0.01\right.$ and $F_{6,90}=3.27, p<0.01$ for right and left carotid, respectively). When similar analyses were employed on brain-irrigating arteries downstream of the ACA, iv LPS injection was found to result in significantly lower blood flow compared to iv saline administration in the azygos pericallosal artery $\left(F_{1,15}=9.75, p<0.01\right.$; Fig. $\left.2 \mathrm{E}\right)$ while flow globally significantly increased over time $\left(F_{6,90}=3.20, p<0.01\right)$. The anterior amygdaloid arteries showed a tendency $\left(F_{6,90}=2.08, p=0.063\right)$ and a significant interaction $\left(F_{6,90}=2.36, p<0.05\right)$ between iv treatment and time after injection for this vessel in the right and left hemisphere, respectively. Post-hoc tests did however not indicate any differences between iv LPS and saline treatments at the different time points after injection in this artery (Fig. 2D).

\section{Iv LPS increased cerebral expression of prostaglandin $\mathrm{H}_{2}$ - and $E_{2}$-synthesizing enzymes}

The assumptions for application of the comparative $\mathrm{C}_{\mathrm{T}}$ method are that amplification efficiencies of cDNAs of genes of interest and that of cDNA of the control gene are similar and close to 1 . In the present conditions the efficiency of cDNA amplification of the control actin was 0.9 and that of genes of interest 0.98-1.06, a difference that may affect fold changes of expression. The expression of genes for which a oneway ANOVA on $2{ }^{-\Delta C}$ data, the calculation of which presupposes amplification efficiencies close to 1 (Schmittgen and Livak, 2008), indicated a significant difference were therefore further analyzed using the Relative Expression Software Tool (REST) for group-wise comparison and statistical analysis of relative expression that takes into account real amplification efficiencies (Pfaffl et al., 2002).

Isoflurane anesthesia, like other anesthetics, has been shown to exert anti-inflammatory effects and to attenuate LPS-induced TNF $\alpha$ expression in peripheral tissues (de Rossi et al., 2004; Flondor et al., 2008). Induction of classical inflammatory molecules in the brain was therefore studied before addressing the effect of iv LPS on the cerebral expression of vasoactive mediators. TNF $\alpha$ and MCP-1/CCL2 mRNAs in the brain increase after peripheral administration of LPS in mice (Layé et al., 1994; Reyes et al., 2003) and were therefore used as positive controls in the present study. Analyses of $2 \bar{T}^{-\Delta C}$ and fold changes of MCP-1/CCL2 and TNF $\alpha$ mRNAs indicated significant increases $2.5 \mathrm{~h}$ after iv LPS treatment with expressions being 4.0 and 12.4 times higher, respectively, as compared to administration of its vehicle (Table 1). The iv LPS-induced increase in TNF $\alpha$ mRNA under isoflurane anesthesia found in the present study was larger than that reported at a comparable time point after iv administration of a similar dose of LPS, but under ketamine-medetomodine anesthesia (Ruiz-Valdepenas et al., 2011). Thus, even though isoflurane may exert anti-inflammatory effects, it seems less important than for some other types of anesthesia and still allows for the study of cerebral expression of inflammatory mediators. 

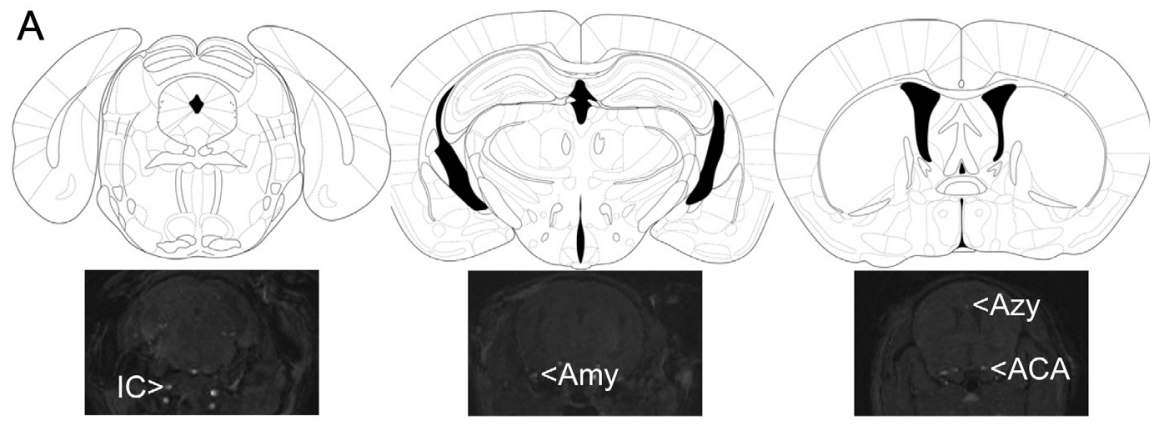

B Left internal carotid

C

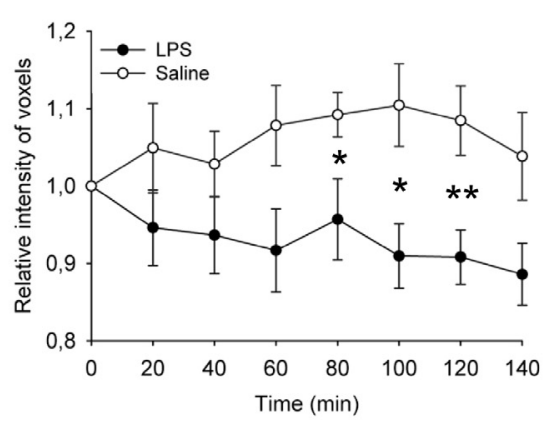

D Left anterior amygdaloid artery

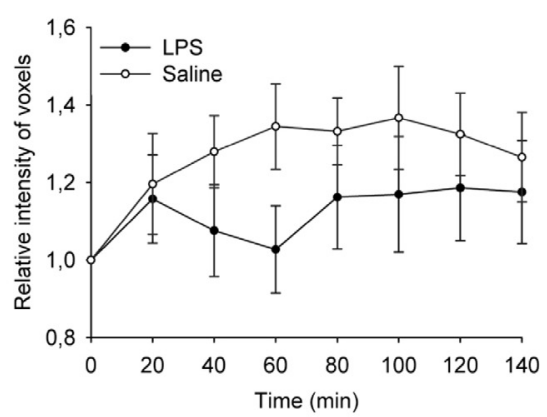

E

Azygos pericallosal artery

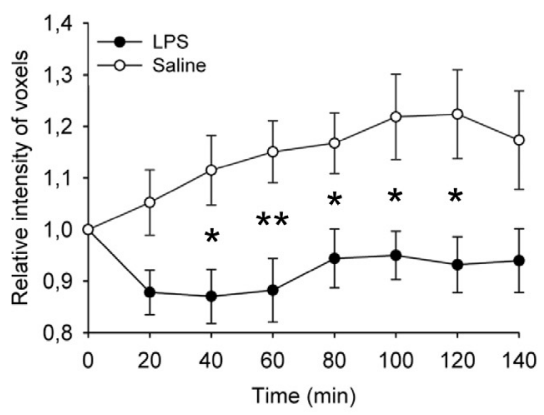

Fig. 2. Flow estimation in the mouse internal carotid arteries, $A C A$, anterior amygdaloid artery and azygos pericallosal artery with 3D TOF-MRA. The top part illustrates the levels at which ROIs were placed to measure the mean intensity of voxels in these arteries (A). Plates from mouse brain atlas (Paxinos and Franklin, 2001) indicate brain levels corresponding to the levels at which vessels were analyzed (A). The relative intensity of voxels in the internal carotid arteries (B), ACA (C), anterior amygdaloid artery (D) and azygos pericallosal artery (E) at different time points after iv LPS or saline injection are shown in graphs. ACA: anterior cerebral artery, Amy: amygdaloid artery, Azy: azygos pericallosal artery, IC: internal carotid (upstream of and as part of the circle of Willis). ${ }^{*} p<0.05,{ }^{* *} p<0.01$. Group sizes Sal: $n=9-10$; LPS: $n=9-10$.

A one-way ANOVA on $2_{\bar{T}}^{-\Delta C}$ COX-2 mRNA data indicated significantly higher expression after iv LPS administration than after iv saline injection. REST analysis confirmed this effect and allowed to determine that COX-2 mRNA expression was 2.4 times higher in LPS-treated mice than in animals that received saline (Table 1). A oneway ANOVA on $2 \bar{T}^{\Delta C}$ mPGES mRNA data indicated significantly higher expression $2.5 \mathrm{~h}$ after iv LPS administration as compared to iv saline injection (Table 1). However, when taking into account real amplification efficiencies in the REST analysis this effect was reduced to one at the limit of significancy with a 1.4 times higher mPGES mRNA expression in LPS-treated mice than in animals that were given saline (Table 1). Analyses of $2^{-\Delta C}$ and fold change of preproET-1 and iNOS mRNAs data did not reveal any significant differences between LPS and saline treatment $2.5 \mathrm{~h}$ after their iv administration (Table 1).

\section{Iv LPS-induced inflammatory signaling and prostaglandin synthesis did not occur in cerebral arteries}

c-Fos. The lower flow in the ACA and in the internal carotids within the circle of Willis of mice injected with LPS as compared to those administered saline may therefore be related to differences in neuronal activity in the cerebral territories supplied by these arteries. As the preoptic region and the supraoptic and paraventricular nuclei of the hypothalamus receive their blood supply largely from the ACA and internal carotids (Ambach and Palkovits, 1974a,b; Ambach et al., 1978), the neuronal activation marker c-Fos was detected in these structures by immunohistochemistry and compared between iv saline- and iv LPS-injected animals. Although no differences in the number of c-Fosimmunoreactive cells were observed between treatments in the ventromedial preoptic area (saline: 15.5 $\pm 8.2 ; \quad$ LPS $20.4 \pm 7.1 ; \quad U=4.0$, $\left.n_{\text {sal }}=3, \quad n_{\text {LPS }}=4, \quad p>0.10\right)$ and the supraoptic nucleus (saline: 8.3 $\pm 2.4 ;$ LPS $11.9 \pm 3.2 ; \quad U=6.0$, $n_{\text {sal }}=4, \quad n_{\text {LPS }}=4, p>0.10$ ), LPS treatment was found to decrease the number of c-Fos-positive cells in the paraventricular nucleus of the hypothalamus (saline: $73.3 \pm 3.4$; LPS $41.3 \pm 4.7 ; \quad U=0.0, n_{\text {sal }}=3$, $n_{\text {LPS }}=3, p<0.05$ ).

$N K-\kappa B$. In contrast to c-Fos induction, the expression of which can be provoked by a wide variety of stimuli, the nuclear translocation of $\mathrm{NF}-\mathrm{kB}$ occurs more specifically in response to inflammatory stimuli, including LPS and proinflammatory cytokines (D'Acquisto et al., 1997; Abate et al., 1998). The overall pattern of NF-kBimmunoreactivity in the brain obtained after iv LPS injection was very much reminiscent of that reported after systemic administration of the pro-inflammatory cytokine interleukin-1ß in mice (Nadjar et al., 2003). In particular, the vasculature between the forebrain hemispheres where the azygos pericallosal artery runs and that of the 
Table 1. Effects of iv LPS on cerebral expression of inflammation-inducible enzymes producing vasoactive mediators and cytokines

\begin{tabular}{|c|c|c|c|c|}
\hline Gene & $2^{-\Delta C_{\top}}( \pm S E M)$ & ANOVA & Fold change (Standard error) & REST \\
\hline $\operatorname{cox}-2$ & $\begin{array}{l}\text { Sal: } 3.73 E-03( \pm 4.05 E-04) \\
\text { PS: } 1.83 E-02( \pm 2.57 E-03)\end{array}$ & $\begin{array}{l}\text { LPS }>\text { Sal } \\
p<0.01\end{array}$ & $2.423(1.109-5.690)$ & $\begin{array}{l}\text { LPS }>\text { Sa } \\
p<0.01\end{array}$ \\
\hline ET-1 & $\begin{array}{l}\text { Sal: } 9.52 \mathrm{E}-02( \pm 3.33 \mathrm{E}-02 \\
\text { LPS: } 1.03 \mathrm{E}-01( \pm 2.35 \mathrm{E}-02)\end{array}$ & NS & - & \\
\hline iNOS & $\begin{array}{l}\text { Sal: } 1.27 \mathrm{E}-05( \pm 3.01 \mathrm{E}-06) \\
\text { LPS: } 1.24 \mathrm{E}-04( \pm 8.64 \mathrm{E}-05)\end{array}$ & NS & - & \\
\hline mPGES & $\begin{array}{l}\text { Sal: } 1.64 \mathrm{E}-03( \pm 4.72 \mathrm{E}-05) \\
\text { LPS: } 3.72 \mathrm{E}-03( \pm 5.01 \mathrm{E}-04\end{array}$ & $\begin{array}{l}\text { LPS }>\text { Sal } \\
p<0.01\end{array}$ & $1.430(0.639-3.104)$ & $\begin{array}{l}\text { LPS > Sa } \\
p=0.051\end{array}$ \\
\hline MCP-1/CCL2 & $\begin{array}{l}\text { Sal: } 1.09 \mathrm{E}-03( \pm 3.79 \mathrm{E}-04) \\
\text { LPS: } 1.18 \mathrm{E}-02( \pm 3.91 \mathrm{E}-03)\end{array}$ & $\begin{array}{l}\text { LPS }>\text { Sal } \\
p<0.05\end{array}$ & $4.031(1.283-19.950)$ & $\begin{array}{l}\text { LPS }>\text { Sa } \\
p<0.05\end{array}$ \\
\hline $\mathrm{TNF} \alpha$ & $\begin{array}{l}\text { Sal: } 4.10 E-04( \pm 3.69 E-04) \\
\text { LPS: } 3.67 E-03( \pm 1.13 E-03)\end{array}$ & $\begin{array}{l}\text { LPS }>\text { Sal } \\
p<0.05\end{array}$ & $12.382(1.999-62.299)$ & $\begin{array}{l}\text { LPS }>\text { Sa } \\
p<0.01\end{array}$ \\
\hline
\end{tabular}

ventromedial forebrain meningeal surface containing the preoptic and lateral hypothalamic arteries displayed NFKB-immunoreactivity after iv LPS injection (Fig. 3 left panels). The choroid plexus showed an important concentration of round nuclear-like staining indicating nuclear translocation of NF-кB after iv LPS administration that was absent when the NF- $\mathrm{NB}$ antiserum was omitted (data not shown). Even though the round nuclear labeling was not observed in the absence of the NF- $\mathrm{B}$ antiserum, some cytoplasmatic staining was found. This indicates that, in spite of the reported low cross reactivity with immunoglobulins of other species, the secondary antiserum did recognize some endogenous mouse immunoglobulins in the choroid plexus and meninges giving rise to some cytoplasmatic background staining. However, as only round nuclear-like labeling was taken into account as proxy for nuclear translocation, the cytoplasmatic background staining did generally not hinder analysis.

Since blood flow was found to be lower in the lateral parts of the circle of Willis formed by the internal carotids and in the ACA as well as in some downstream arteries, analyses were focused on these vascular territories. In particular, the azygos pericallosal artery and the preoptic and lateral hypothalamic arteries, which receive their input from the ACA, as well as for the latter from the MCA and internal carotids (Ambach et al., 1978; Dorr et al., 2007), were studied. No or very light nuclear NF-кB-immunoreactivity was seen in vessels of saline-treated mice (Fig. 4A, E and I). IV LPS treatment resulted in nuclear NF- $\mathrm{BB}$-immunoreactivity in meningeal cells and presumable veins (Fig. 4C, G) as these did not display autofluorescence under UV stimulation (Fig. 4D, H). Although several preoptic and lateral hypothalamic arteries, identified by their autofluorescent walls (Fig. $3 \mathrm{~K}, \mathrm{~L}$ ) also showed some nuclear NK-KBimmunoreactivity after iv LPS administration (Fig. 4J), this was of less intensity and much less widespread than in veins.

COX-2. Constitutive expression of COX-2 was observed in neurons of the hippocampus, cerebral cortex and cerebellum, as previously reported (Elmquist et al., 1997; Konsman et al., 2004). The vasculature between the forebrain hemispheres where the azygos

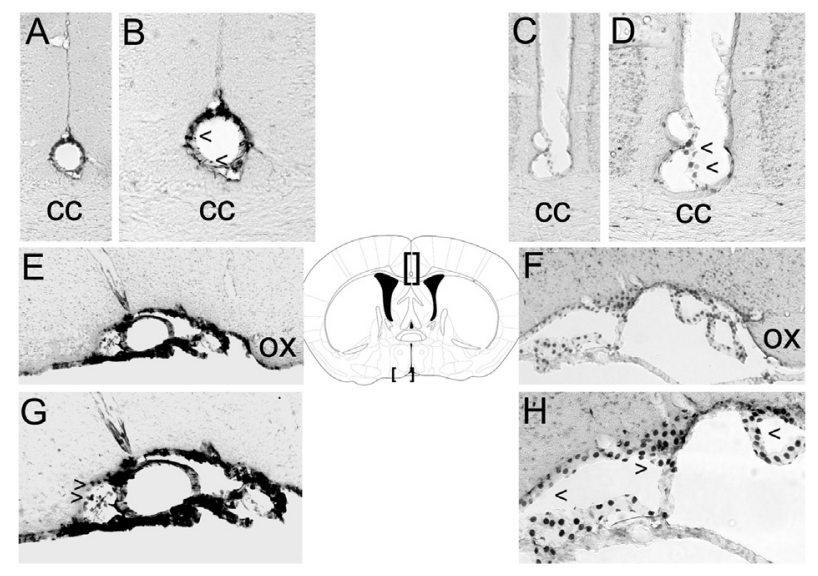

Fig. 3. Photomicrographs illustrating immunoreactivity for the p65 NF- $\kappa B$ subunit $(A, B, E$ and $G)$ and $C O X-2(C, D, F$ and $H)$ between brain hemispheres ( $A, B, C$ and $D)$ and on the ventromedial surface of the forebrain ( $E, F, G$ and $H) 2.5 \mathrm{~h}$ after intravenous injection of bacterial LPS in mice. Higher magnifications of these fields as well as saline controls and identification of vessels are shown in Figs. 4 and 5. cc: corpus callosum. Arrow heads $>$ and $<$ indicate labeling.

pericallosal artery runs and that of the ventromedial forebrain meningeal surface containing the preoptic and lateral hypothalamic arteries showed COX-2immunoreactivity after iv LPS administration (Fig. 3 right panels). No or very light disk-shaped endothelial COX-2immunoreactivity was seen in the vessels between the two forebrain hemispheres of saline-treated mice (Fig. 5A). In contrast, strong endothelial COX-2immunoreactivity with characteristic disk-shaped perinuclear labeling was observed in interhemsipheric vessels of mice injected iv with LPS (Fig. 5C). Neither constitutive neuronal nor LPS-induced vascular-associated labeling was observed when the COX-2 antiserum was omitted (data not shown). Since the vessels in which COX-2 was induced between the two hemispheres did not show UV-induced autofluorescence (Fig. 5D), they were considered to be veins and venules. At the ventral surface of the forebrain, several vessels were found to strongly express COX-2 in the meninges of LPS-treated animals (Fig. 5E). These vessels were identified as veins since they did not display autofluorescence under UV stimulation (Fig. 5F). When patterns of COX-2-immunoreactivity 
in the ventral meninges were compared between mice injected with saline and those that were administered LPS, it turned out that many strongly COX-2-positive vessels were found in proximity to vessels lacking clear labeling in both experimental conditions (Fig. 5G, I). In either condition, preoptic and lateral hypothalamic arteries identified by their autofluorescent walls (Fig. $5 \mathrm{H}, \mathrm{J}$ ) failed to show COX-2 immunoreactivity.

Nitrotyrosine. During inflammation, the production of important quantities of $\mathrm{NO}$ often occurs in parallel with that of reactive oxygen species and gives rise to the formation peroxynitrite, which, in turn, rapidly reacts with tyrosine residues to yield nitrotyrosine (Berg et al., 2011). In the large vessels of the meninges, no clear differences in nitrotyrosine immunoreactivity were found between animals that received iv LPS $2.5 \mathrm{~h}$ earlier and those that were given its saline vehicle (Fig. 6A, B). This lack of difference between groups was not due to a technical failure since we were able to detect occasional nitrotyrosine-immunoreactive vessels and perivascular cells (Fig. 6C, D). Furthermore, neurons in the cerebellum of a mouse euthanized immediately after intraperitoneal injection of LPS were stained with our protocol (data not shown). This finding is in accordance with previous observations in naïve mice (Mehl et al., 1999; Rodrigo et al., 2001). Moreover, these cerebellar neurons showed increased nitrotyrosine-immunoreactivity in a mouse that was allowed to survive $6 \mathrm{~h}$ after intraperitoneal injection of LPS $(10 \mu \mathrm{g}$ corresponding to $300 \mu \mathrm{g} / \mathrm{kg}$ ) (data not shown). Finally, positive signals were obtained throughout sections when they were artificially nitrosylated by incubating them in $1 \mathrm{mM}$ sodium nitrite- and $1 \mathrm{mM} \mathrm{H}_{2} \mathrm{O}_{2}$ containing $0.1 \mathrm{M}$ sodium acetate buffer $(\mathrm{pH}$ 5.0) for 20 min prior to the immunohistochemistry protocol (data not shown).

\section{DISCUSSION}

Time-resolved TOF MRA revealed no differences in blood flow in the internal carotids upstream of the circle of Willis, but indicated lower flow in its lateral parts as well as in the middle and anterior cerebral arteries after intravenous LPS injection as compared to saline administration. Intravenous LPS increased cerebral expression of COX2 and prostaglandin $E$ synthase mRNAs, but this de novo expression occurred in veins rather than in arteries.

The increase in blood flow in the circle of Willis and brain irrigating arteries over time after iv saline administration in control mice as shown by MRA in the present work corroborates results of previous studies measuring cerebral blood flow with arterial spin labeling and laser speckle flowmetry in intact rodents under isoflurane anesthesia (Sicard et al., 2003; Duong, 2007; Shin et al., 2007). This isoflurane-induced rise in cerebral blood flow is partly mediated by increased NO production in the brain (McPherson et al., 1994; Kehl et al., 2002; Sjakste et al., 2005). However, one needs to bear in mind that other inhaled anesthetics, at the same level of anesthesia, increase cerebral blood flow even more (Holmstrom and Akeson, 2005). Hence, given the necessity for a stable level of anesthesia for the present exper-
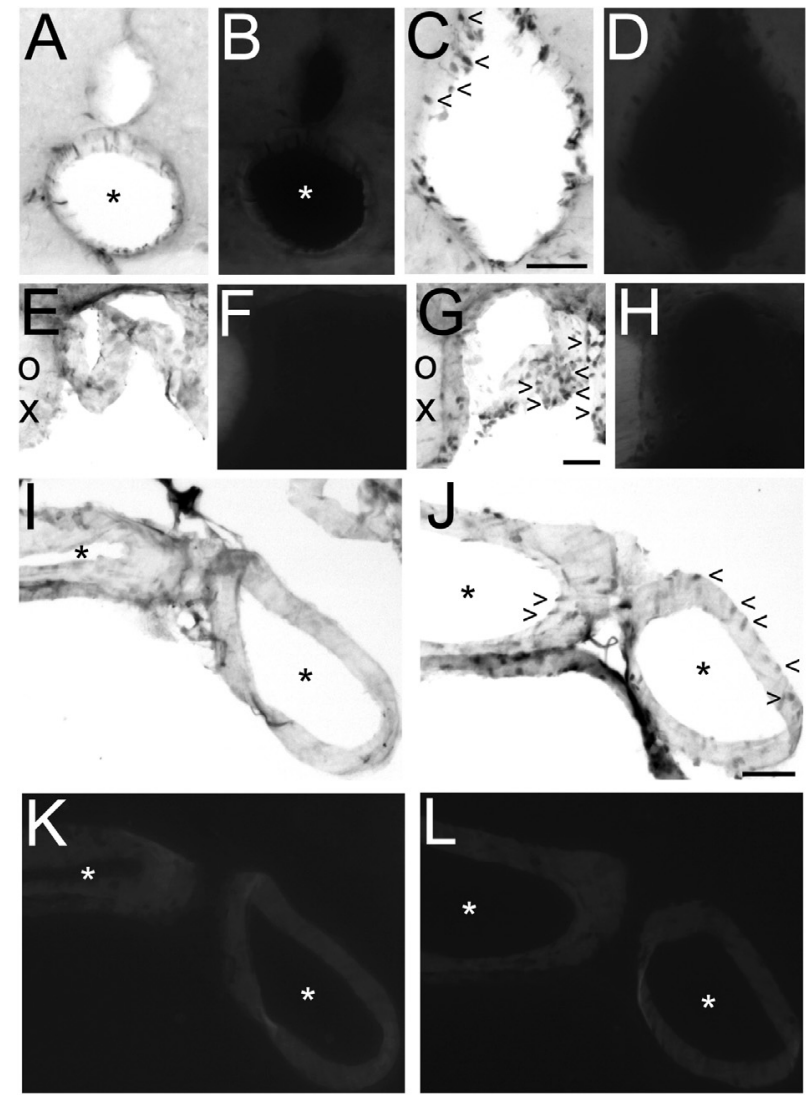

Fig. 4. Photomicrographs illustrating immunoreactivity for the p65 $N F-\kappa B$ subunit between forebrain hemispheres (A and $C$ ) and on the ventral surface of the forebrain (E, G, I and J) $2.5 \mathrm{~h}$ after intravenous injection of saline (A, E and I) or bacterial LPS (C, G and J) in mice. Dark images show autofluorescent arteries under UV light stimulation of the fields shown in bright field images immediately left or above them. ox: optic chiasm. Arrow heads $>$ and $<$ indicate labeling. *Arteries. Scale bars $=100 \mu \mathrm{m}$.

iments, an informed choice in favor of isoflurane was made in the present work.

The MRA findings obtained after iv LPS injection in mice are in accordance with clinical observations and expand experimental data. Indeed, clinical studies have observed anatomical signs of vasospasms in proximate branches of the ACA and MCA using MRA during sepsis-associated encephalopathy (Bartynski et al., 2006; Polito et al., 2013). Moreover, flow speed in the territory of the MCA, as measured with transcranial Doppler, is reduced after iv LPS administration in healthy volunteers (Brassard et al., 2012). However, no animal study so far has studied blood flow in the ACA and MCA and their proximate branches in experimental sepsis models. We were able to show, using 3D MRA, that iv LPS reduced flow in the ACA and one of its branches, the azygos pericallosal artery. Our findings expand experimental observations of increased resting blood flow velocity in the sensory cortex and vasodilation of subpial thirdorder arterioles and venules after iv administration of comparable doses of LPS in mice (Rosengarten et al., 2007, 2008; Ruiz-Valdepenas et al., 2011). This vasodilatation in arterioles downstream of the ACA and MCA 


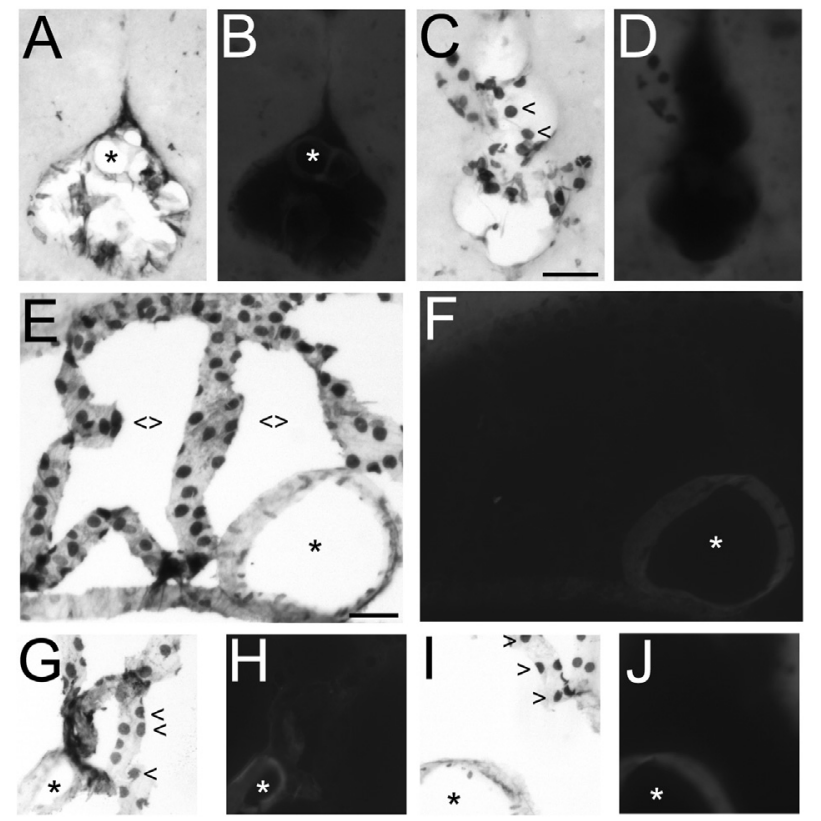

Fig. 5. Photomicrographs illustrating the distribution of COX-2-ir between forebrain hemispheres $(A$ and $C$ ) and on the ventral surface of the forebrain ( $E, G$ and I) $2.5 \mathrm{~h}$ after intravenous injection of saline (A and $\mathrm{G}$ ) or bacterial LPS (C, G and J) in mice. Dark images show autofluorescent arteries under UV light stimulation of the fields shown in bright field images immediately left of them. Arrow heads $>$ and $<$ indicate labeling. "Arteries. Scale bars $=100 \mu \mathrm{m}$.

may represent a physiological response to the reduced flow in these arteries after iv LPS administration. However, the finding that iv LPS decreases sensory stimulation-evoked blood flow responses in the cortex prior to, and, later on, in spite of, increased resting flow velocity indicates dysfunctional neurovascular coupling (Rosengarten et al., 2007) and may be explained by lower flow in upstream cerebral arteries as observed in the present work.

The time-resolved 3D MRA results obtained here also expand clinical observations in that they allow for quantitative measurements in high-flow systems and may therefore reveal hypo- or dysfunction well before anatomical signs of vasospasms would be visible on routinely used clinical MRA. Thus, our findings indicate that blood flow in the first segments of the mouse ACA and MCA is lower after iv LPS injection as compared to administration of its vehicle. Importantly, with timeresolved 3D MRA we were also able to show that flow in the carotid arteries downstream of the brain was not different between iv LPS and saline treatment. It was only when the internal carotids become part of the circle of Willis that flow turned out to be lower in iv LPSinjected mice than in control animals. These are important observations as they indicate that reduced flow in the first segments of the ACA and MCA during sepsis is not necessarily the consequence of systemic hypotension during bacteremia, but rather due to altered vasoregulation within the circle of Willis and in more downstream brain-irrigating arteries.

To identify potential mechanisms underlying decreased blood flow in the ACA and azygos

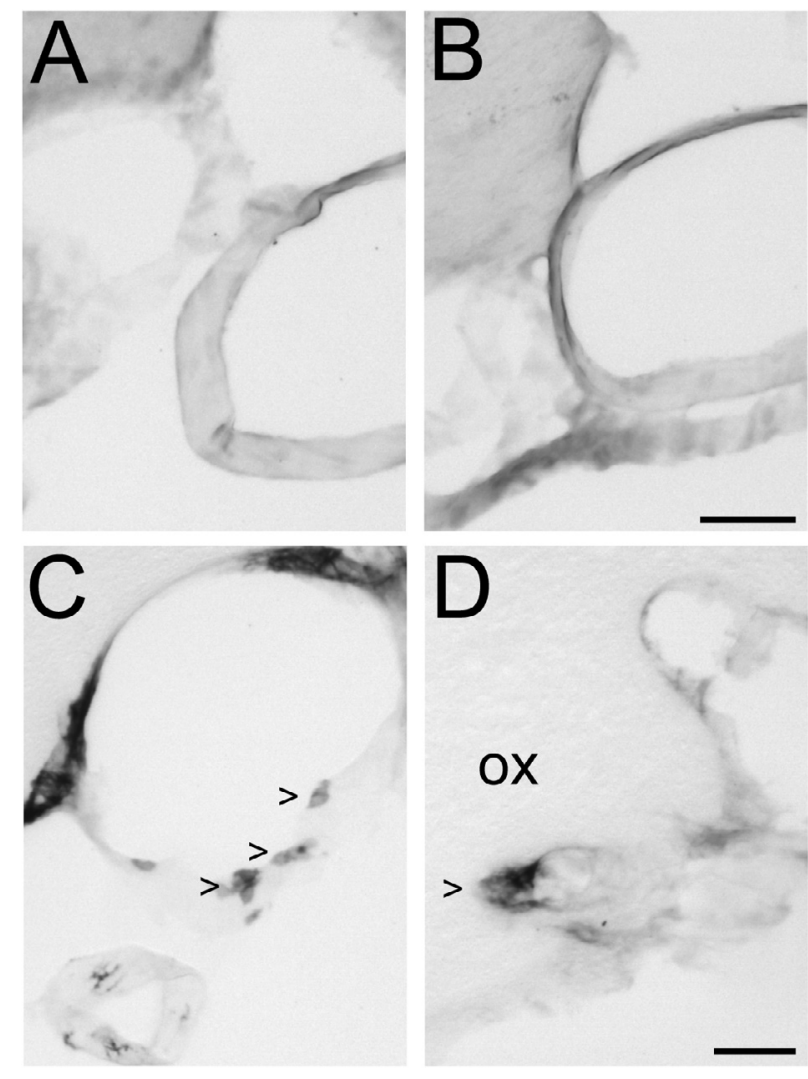

Fig. 6. Photomicrographs illustrating immunoreactivity for nitrotyrosine on the ventral surface of the forebrain $2.5 \mathrm{~h}$ after intravenous injection of saline $(A)$ or bacterial LPS (B, C and D) in mice. ox: optic chiasm. Arrow head $>$ indicates labeling. Scale bars $=100 \mu \mathrm{m}$.

pericallosal artery, we assessed the cerebral production of prostaglandins, NO and ET-1 as vasoactive mediators. ET-1 can be produced by cerebrovascular endothelial cells and is one of the most potent vasoconstrictors of cerebral arteries (Salom et al., 1995). Although peripheral administration of LPS in rodent has been reported to increase preproET-1 mRNA in the frontal cortex (Shimojo et al., 2006), no differences in whole-brain preproET-1 mRNA expression were observed between iv LPS- and saline-treated mice in the present work. This apparent discrepancy can be explained by the fact that contrary to the previously published study, cells present in the circulatory system of the brain were rinsed with PBS in the present work. Indeed, murine mononuclear leukocytes produce prepro ET-1 mRNA in response to LPS (Wahl et al., 2005) and human circulating monocytes of septic patients contain significantly more ET-1 mRNA than those of healthy controls (Ebihara et al., 1998). Since the ACA and MCA as well as meningeal and pial arteries express the endothelin A receptor (De Oliveira et al., 1995; Pierre and Davenport, 1995; Hansen-Schwartz et al., 2002), this raises the possibility that ET-1 produced by circulating monocytes may exert vasoconstrictive effects on cerebral arteries during systemic inflammation. This hypothesis may be tested by repeating the experiments described here in wild-type mice 
that have received bone marrow depletion followed by transplantation with ET-1-deficient cells.

During systemic inflammation, the production of large quantities of NO by iNOS often occurs in parallel with that of reactive oxygen species and gives rise to the formation peroxynitrite (Berg et al., 2011). This highly reactive molecule can nitrosylate proteins and stimulate contraction of smooth muscle cells of cerebral arteries (Elliott et al., 1998). However, we found neither increased cerebral iNOS mRNA expression nor evidence of nitrosylation of tyrosine residues in brain arteries $2.5 \mathrm{~h}$ after iv LPS injection. The absence of increased iNOS mRNA expression during the first hours after iv LPS administration may be explained by its long induction time. In fact, only direct injection of LPS into the brain seems to result in a slight elevation of iNOS mRNA $2 \mathrm{~h}$ later (Okamoto et al., 1998). Instead, it takes $6 \mathrm{~h}$ to observe a robust increase in iNOS mRNA regardless of whether LPS was administered intracerebrally or systemically (Wong et al., 1996; Okamoto et al., 1998).

Although COX-2 within the context of inflammation is best known as the form of COX that is inducible by inflammatory mediators, it is important to point out that COX-2 is constitutively present in neurons and involved in the physiological coupling of neuronal activity and local changes in cerebral blood flow (Stefanovic et al., 2006). Our RT-PCR analyses showed that iv LPS increased cerebral COX-2 mRNA expression to a similar extent as previously reported under comparable experimental conditions (Ruiz-Valdepenas et al., 2011). In addition to its proper biological effects, COX-2-derived prostaglandin $\mathrm{H}_{2}$ also constitutes an intermediate for the production of other vasoactive prostaglandins. Interestingly, we found that mPGES mRNA expression increased to a lesser extent than COX-2 mRNA after iv LPS. This differentially increased expression of COX-2 and mPGES after iv LPS suggests that not all prostaglandin $\mathrm{H}_{2}$ produced will be immediately transformed into prostaglandin $\mathrm{E}_{2}$ and that both mediators may potentially exert vasoactive effects.

To determine if de novo synthesis of prostaglandinsynthesizing enzymes occurred in brain-irrigating arteries, immunohistochemical detection of the transcription factor NF- $\mathrm{B}$, essential for COX-2 transcription (D'Acquisto et al., 1997; Abate et al., 1998), as well as of COX-2 was employed. We observed that iv LPS treatment resulted in nuclear NF-kBimmunoreactivity mostly in veins and to a much less important extent in ACA-derived azygos pericallosal artery and preoptic and lateral hypothalamic arteries in the meninges. We have previously shown that LPSinduced COX-2 expression does not occur in alkaline phosphatase-positive arterioles of the brain parenchyma (Konsman et al., 2004). However, this marker does not label meningeal arteries. Since rodent cerebral arteries rapidly respond to LPS in vitro by increasing COX-2 expression (Hernanz et al., 2004), we set out to determine if meningeal arteries express COX-2 after iv LPS administration. In the present work, COX-2-immunoreactivity was observed in medium-sized and large vessels, often adjacent to arteries, but both in iv saline- and LPS- treated animals, even though it tended to be stronger in the latter. The presence of COX-2-immunoreactivity in cerebral vessels, presumably veins, of saline-injected rodents is in contrast to our previous findings obtained in animals that had not undergone isoflurane anesthesia (Konsman et al., 2004), but may represent a biological response to isoflurane-induced reduction of cerebral prostaglandin $\mathrm{E}_{2}$ contents (Sato et al., 1995).

The absence of iv LPS-induced COX-2 expression in ACA-derived arteries observed here expands previous incidental mention of the lack of COX-2 expression in arteries identified by Giemsa stain after iv LPS administration (Elmquist et al., 1997). mPGES is found in COX-2-positive vessels in the meninges and the brain parenchyma after peripheral LPS administration, but also seems to be absent from "artery-like" vessels, based on morphological criteria (Yamagata et al., 2001; Eskilsson et al., 2014). So even though prostaglandin $\mathrm{H}_{2}$, induces vasoconstriction in cerebral arteries (Toda et al., 1988; Davidge, 2001) and prostaglandin $E_{2}$ promotes vasoconstriction in cerebral arteries and cortical arterioles (Jadhav et al., 2004; Dabertrand et al., 2013), their respective synthesizing enzymes are not induced in these vessels, but rather in adjacent veins, during systemic inflammation. Interestingly, systemic LPS administration also increases blood-borne prostaglandin $\mathrm{E}_{2}$ (Tavares et al., 2006) and prostaglandin $\mathrm{E}$ receptors in large cerebral arteries and brain arterioles mediate vasoconstriction (Jadhav et al., 2004; Dabertrand et al., 2013). It is therefore possible that circulating, rather than locally produced, prostaglandin $E_{2}$ mediates vasoconstrictive effects on cerebral arteries during systemic inflammation.

A rise in neuronal activity increases local as well as more upstream pial arterial blood flow (ladecola, 2004). As the preoptic region and the supraoptic and paraventricular nuclei of the hypothalamus receive their blood supply largely from the ACA and internal carotids (Ambach and Palkovits, 1974a,b; Ambach et al., 1978), important changes in neuronal activity in these hypothalamic structures may have contributed to the differences in cerebral blood flow in these vessels between systemic saline and LPS administration. In the present work the number of cells expressing the activation marker c-Fos was not different between treatments in these structures, except for the paraventricular nucleus of the hypothalamus $(\mathrm{PVH})$ where LPS was found to reduce expression of this cellular activation marker. These findings are at variance with previous reports, including our own, showing increased c-Fos expression in these rodent brain structures after systemic LPS administration in awake animals (Konsman et al., 1999). Although the fact that LPS was injected in anesthesized animals in the present work may account for the absence of increased c-Fos expression in the ventromedian preoptic and supraoptic hypothalamus, this cannot explain reduced cellular activation in the $\mathrm{PVH}$. With respect to the latter finding it is important to consider that, unlike in awake animals, cFos expression in this structure was already abundant in animals that received saline under isoflurane anesthesia. Although, exposure to anesthesia maintaining concentrations of isoflurane $(0.6-1.5 \%)$ alone is not sufficient to 
induce c-Fos expression in the PVH (Sawamura et al., 2004), both exposure to magnetic fields and radiofrequencies can increase c-Fos expression in the PVH ( $\mathrm{Ji}$ et al., 1998; Jorge-Mora et al., 2011). Since MRI involves both exposure to a magnetic field and to various radio waves, the high baseline c-Fos expression observed in the PVH may be related to our methodological choices. The fact that LPS then lowers PVH c-Fos expression in this context may not necessarily be relevant to the pathophysiology of sepsis and its complications. In addition, it is also important to keep in mind that the PVH contains only 21.500 neurons and represents $0.36 \mathrm{~mm}^{3}$ (Kiss et al., 1991) and thus constitutes less than $5 \%$ of the rodent hypothalamus, which comprises about $10 \mathrm{~mm}^{3}$ (Bouilleret et al., 2009). It seems therefore unlikely that the lower arterial cerebral blood flow in the ACA and internal carotids of LPS-treated mice compared to their salineinjected controls was related to changes in neuronal activity in the hypothalamus.

\section{CONCLUSION}

Our work indicates that during LPS-induced systemic inflammation no changes occur in the filling of the circle of the Willis from the periphery, but that circulating LPS alters outflow from the circle of Willis to the middle and anterior cerebral arteries. These modifications in arterial flow were not related to increased cerebral synthesis of prostaglandins, but may be the consequence of the action of circulating prostaglandins and other vasoactive mediators on brain-irrigating arteries during systemic inflammation.

Acknowledgments-This work was supported by grants from the interdisciplinary CNRS-INSERM Small Animal Imaging and the CNRS Longevity programs.

\section{REFERENCES}

Abate A, Oberle S, Schroder H (1998) Lipopolysaccharide-induced expression of cyclooxygenase- 2 in mouse macrophages is inhibited by chloromethylketones and a direct inhibitor of NFkappa B translocation. Prostaglandins Other Lipid Mediat 56:277-290.

Ambach G, Palkovits M (1974a) Blood supply of the rat hypothalamus. I. Nucleus supraopticus. Acta Morphol Acad Sci Hung 22:291-310.

Ambach G, Palkovits M (1974b) Blood supply of the rat hypothalamus. II. Nucleus paraventricularis. Acta Morphol Acad Sci Hung 22:311-320.

Ambach G, Kivovics P, Palkovits M (1978) The arterial and venous blood supply of the preoptic region in the rat. Acta Morphol Acad Sci Hung 26:21-41.

Baron RM, Baron MJ, Perrella MA (2006) Pathobiology of sepsis: are we still asking the same questions? Am J Respir Cell Mol Biol 34:129-134.

Bartynski WS, Boardman JF, Zeigler ZR, Shadduck RK, Lister J (2006) Posterior reversible encephalopathy syndrome in infection, sepsis, and shock. Am J Neuroradiol 27:2179-2190.

Berg RM, Moller K, Bailey DM (2011) Neuro-oxidative-nitrosative stress in sepsis. J Cereb Blood Flow Metab 31:1532-1544.

Blank C, Luz A, Bendigs S, Erdmann A, Wagner H, Heeg K (1997) Superantigen and endotoxin synergize in the induction of lethal shock. Eur J Immunol 27:825-833.
Bouilleret V, Hogan RE, Velakoulis D, Salzberg MR, Wang L, Egan GF, O'Brien TJ, Jones NC (2009) Morphometric abnormalities and hyperanxiety in genetically epileptic rats: a model of psychiatric comorbidity? Neurolmage 45:267-274.

Bowton DL, Bertels NH, Prough DS, Stump DA (1989) Cerebral blood flow is reduced in patients with sepsis syndrome. Crit Care Med 17:399-403.

Brassard P, Kim YS, van Lieshout J, Secher NH, Rosenmeier JB (2012) Endotoxemia reduces cerebral perfusion but enhances dynamic cerebrovascular autoregulation at reduced arterial carbon dioxide tension. Crit Care Med 40:1873-1878.

Dabertrand F, Hannah RM, Pearson JM, Hill-Eubanks DC, Brayden JE, Nelson MT (2013) Prostaglandin E2, a postulated astrocytederived neurovascular coupling agent, constricts rather than dilates parenchymal arterioles. J Cereb Blood Flow Metab 33:479-482.

D'Acquisto F, luvone T, Rombola L, Sautebin L, Di Rosa M, Carnuccio R (1997) Involvement of NF-kappaB in the regulation of cyclooxygenase-2 protein expression in LPS-stimulated $\mathbf{J 7 7 4}$ macrophages. FEBS Lett 418:175-178.

Davidge ST (2001) Prostaglandin H synthase and vascular function. Circ Res 89:650-660.

De Oliveira AM, Viswanathan M, Capsoni S, Heemskerk FM, Correa FM, Saavedra JM (1995) Characterization of endothelinA receptors in cerebral and peripheral arteries of the rat. Peptides 16:139-144.

de Rossi LW, Brueckmann M, Rex S, Barderschneider M, Buhre W, Rossaint R (2004) Xenon and isoflurane differentially modulate lipopolysaccharide-induced activation of the nuclear transcription factor KB and production of tumor necrosis factor-alpha and interleukin-6 in monocytes. Anesth Analg 98:1007-1012.

Dorr A, Sled JG, Kabani N (2007) Three-dimensional cerebral vasculature of the CBA mouse brain: a magnetic resonance imaging and micro computed tomography study. Neurolmage 35:1409-1423.

Duong TQ (2007) Cerebral blood flow and BOLD fMRI responses to hypoxia in awake and anesthetized rats. Brain Res 1135:186-194.

Ebersoldt M, Sharshar T, Annane D (2007) Sepsis-associated delirium. Intensive Care Med 33:941-950.

Ebihara I, Nakamura T, Shimada N, Shoji H, Koide H (1998) Effect of hemoperfusion with polymyxin B-immobilized fiber on plasma endothelin-1 and endothelin-1 mRNA in monocytes from patients with sepsis. Am J Kidney Dis 32:953-961.

Ek M, Engblom D, Saha S, Blomqvist A, Jakobsson PJ, EricssonDahlstrand A (2001) Inflammatory response: pathway across the blood-brain barrier. Nature 410:430-431.

Elliott SJ, Lacey DJ, Chilian WM, Brzezinska AK (1998) Peroxynitrite is a contractile agonist of cerebral artery smooth muscle cells. Am J Physiol 275:H1585-1591.

Elmquist JK, Breder CD, Sherin JE, Scammell TE, Hickey WF, Dewitt D, Saper CB (1997) Intravenous lipopolysaccharide induces cyclooxygenase 2-like immunoreactivity in rat brain perivascular microglia and meningeal macrophages. J Comp Neurol 381:119-129.

Eskandari MK, Bolgos G, Miller C, Nguyen DT, DeForge LE, Remick DG (1992) Anti-tumor necrosis factor antibody therapy fails to prevent lethality after cecal ligation and puncture or endotoxemia. J Immunol 148:2724-2730.

Eskilsson A, Tachikawa M, Hosoya K, Blomqvist A (2014) Distribution of microsomal prostaglandin E synthase-1 in the mouse brain. $J$ Comp Neurol 522:3229-3244.

Faraci FM, Brian Jr JE (1994) Nitric oxide and the cerebral circulation. Stroke 25:692-703.

Flondor M, Hofstetter C, Boost KA, Betz C, Homann M, Zwissler B (2008) Isoflurane inhalation after induction of endotoxemia in rats attenuates the systemic cytokine response. Eur Surg Res 40:1-6.

Hansen-Schwartz J, Szok D, Edvinsson L (2002) Expression of ET (A) and $E T(B)$ receptor mRNA in human cerebral arteries. $B r ~ J$ Neurosurg 16:149-153. 
Hernanz R, Briones AM, Alonso MJ, Vila E, Salaices M (2004) Hypertension alters role of iNOS, COX-2, and oxidative stress in bradykinin relaxation impairment after LPS in rat cerebral arteries. Am J Physiol 287:H225-234.

Heyland DK, Hopman W, Coo H, Tranmer J, McColl MA (2000) Longterm health-related quality of life in survivors of sepsis. Short Form 36: a valid and reliable measure of health-related quality of life. Crit Care Med 28:3599-3605.

Holmstrom A, Akeson J (2005) Desflurane induces more cerebral vasodilation than isoflurane at the same A-line autoregressive index level. Acta Anaesthesiol Scand 49:754-758.

ladecola C (2004) Neurovascular regulation in the normal brain and in Alzheimer's disease. Nat Rev Neurosci 5:347-360.

Iwashyna TJ, Ely EW, Smith DM, Langa KM (2010) Long-term cognitive impairment and functional disability among survivors of severe sepsis. JAMA 304:1787-1794.

Jadhav V, Jabre A, Lin SZ, Lee TJ (2004) EP1- and EP3-receptors mediate prostaglandin E2-induced constriction of porcine large cerebral arteries. J Cereb Blood Flow Metab 24:1305-1316.

Ji RR, Schlaepfer TE, Aizenman CD, Epstein CM, Qiu D, Huang JC, Rupp F (1998) Repetitive transcranial magnetic stimulation activates specific regions in rat brain. Proc Natl Acad Sci USA 95:15635-15640.

Jones AE, Puskarich MA (2009) Sepsis-induced tissue hypoperfusion. Crit Care Clin 25:769-779. ix.

Jorge-Mora T, Misa-Agustino MJ, Rodriguez-Gonzalez JA, JorgeBarreiro FJ, Ares-Pena FJ, Lopez-Martin E (2011) The effects of single and repeated exposure to $2.45 \mathrm{GHz}$ radiofrequency fields on c-Fos protein expression in the paraventricular nucleus of rat hypothalamus. Neurochem Res 36:2322-2332.

Kehl F, Shen H, Moreno C, Farber NE, Roman RJ, Kampine JP, Hudetz AG (2002) Isoflurane-induced cerebral hyperemia is partially mediated by nitric oxide and epoxyeicosatrienoic acids in mice in vivo. Anesthesiology 97:1528-1533.

Kingsley K, Carroll K, Huff JL, Plopper GE (2001) Photobleaching of arterial autofluorescence for immunofluorescence applications. Biotechniques 30:794-797.

Kiss JZ, Martos J, Palkovits M (1991) Hypothalamic paraventricular nucleus: a quantitative analysis of cytoarchitectonic subdivisions in the rat. J Comp Neurol 313:563-573.

Konsman JP, Blomqvist A (2005) Forebrain patterns of c-Fos and FosB induction during cancer-associated anorexia-cachexia in rat. Eur J Neurosci 21:2752-2766.

Konsman JP, Kelley K, Dantzer R (1999) Temporal and spatial relationships between lipopolysaccharide-induced expression of Fos, interleukin-1beta and inducible nitric oxide synthase in rat brain. Neuroscience 89:535-548.

Konsman JP, Vigues S, Mackerlova L, Bristow A, Blomqvist A (2004) Rat brain vascular distribution of interleukin-1 type-1 receptor immunoreactivity: relationship to patterns of inducible cyclooxygenase expression by peripheral inflammatory stimuli. J Comp Neurol 472:113-129.

Konsman JP, Veeneman J, Combe C, Poole S, Luheshi GN, Dantzer $R$ (2008) Central nervous action of interleukin-1 mediates activation of limbic structures and behavioural depression in response to peripheral administration of bacterial lipopolysaccharide. Eur J Neurosci 28:2499-2510.

Layé S, Parnet P, Goujon E, Dantzer R (1994) Peripheral administration of lipopolysaccharide induces the expression of cytokine transcripts in the brain and pituitary of mice. Brain Res Mol Brain Res 27:157-162.

Lazosky A, Young GB, Zirul S, Phillips R (2010) Quality of life after septic illness. J Crit Care 25:406-412.

Levy MM, Fink MP, Marshall JC, Abraham E, Angus D, Cook D, Cohen J, Opal SM, Vincent JL, Ramsay G (2003) 2001 SCCM/ ESICM/ACCP/ATS/SIS international sepsis definitions conference. Intensive Care Med 29:530-538.

Maekawa T, Fujii Y, Sadamitsu D, Yokota K, Soejima Y, Ishikawa T, Miyauchi Y, Takeshita H (1991) Cerebral circulation and metabolism in patients with septic encephalopathy. Am J Emerg Med 9:139-143.
McPherson RW, Kirsch JR, Tobin JR, Ghaly RF, Traystman RJ (1994) Cerebral blood flow in primates is increased by isoflurane over time and is decreased by nitric oxide synthase inhibition. Anesthesiology 80:1320-1327.

Mehl M, Bidmon HJ, Hilbig H, Zilles K, Dringen R, Ullrich V (1999) Prostacyclin synthase is localized in rat, bovine and human neuronal brain cells. Neurosci Lett 271:187-190.

Miraux S, Franconi JM, Thiaudiere E (2006) Blood velocity assessment using 3D bright-blood time-resolved magnetic resonance angiography. Magn Reson Med 56:469-473.

Moller K, Strauss GI, Qvist J, Fonsmark L, Knudsen GM, Larsen FS, Krabbe KS, Skinhoj P, Pedersen BK (2002) Cerebral blood flow and oxidative metabolism during human endotoxemia. J Cereb Blood Flow Metab 22:1262-1270.

Nadjar A, Combe C, Laye S, Tridon V, Dantzer R, Amedee T, Parnet $P$ (2003) Nuclear factor kappaB nuclear translocation as a crucial marker of brain response to interleukin-1. A study in rat and interleukin-1 type I deficient mouse. J Neurochem 87:1024-1036.

Okamoto H, Ito O, Roman RJ, Hudetz AG (1998) Role of inducible nitric oxide synthase and cyclooxygenase-2 in endotoxin-induced cerebral hyperemia. Stroke 29:1209-1218.

Pandharipande PP, Girard TD, Jackson JC, Morandi A, Thompson JL, Pun BT, Brummel NE, Hughes CG, Vasilevskis EE, Shintani AK, Moons KG, Geevarghese SK, Canonico A, Hopkins RO, Bernard GR, Dittus RS, Ely EW (2013) Long-term cognitive impairment after critical illness. N Engl J Med 369:1306-1316.

Paxinos G, Franklin KBJ (2001) The mouse brain in stereotaxic coordinates. San Diego: Academic Press.

Pfaffl MW, Horgan GW, Dempfle L (2002) Relative expression software tool (REST) for group-wise comparison and statistical analysis of relative expression results in real-time PCR. Nucleic Acids Res 30:e36.

Pierre LN, Davenport AP (1995) Autoradiographic study of endothelin receptors in human cerebral arteries. J Cardiovasc Pharmacol 26 (Suppl 3):S326-328.

Polito A, Eischwald F, Maho AL, Polito A, Azabou E, Annane D, Chretien F, Stevens RD, Carlier R, Sharshar T (2013) Pattern of brain injury in the acute setting of human septic shock. Crit Care $17: R 204$.

Pourtau L, Heeringa NA, Rovère CAA, Nahon JL, Miraux S, Konsman JP (2014) Increased circulating rather than spinal cytokines accompany chronic pain behaviors in experimental bone cancer and arthritis. Neuroimmunol Neuroinflammation 1:153-160.

Reyes TM, Walker JR, DeCino C, Hogenesch JB, Sawchenko PE (2003) Categorically distinct acute stressors elicit dissimilar transcriptional profiles in the paraventricular nucleus of the hypothalamus. J Neurosci 23:5607-5616.

Rodrigo J, Alonso D, Fernandez AP, Serrano J, Richart A, Lopez JC, Santacana M, Martinez-Murillo R, Bentura ML, Ghiglione M, Uttenthal LO (2001) Neuronal and inducible nitric oxide synthase expression and protein nitration in rat cerebellum after oxygen and glucose deprivation. Brain Res 909:20-45.

Rolfe DF, Brown GC (1997) Cellular energy utilization and molecular origin of standard metabolic rate in mammals. Physiol Rev 77:731-758.

Rosengarten B, Hecht M, Auch D, Ghofrani HA, Schermuly RT, Grimminger F, Kaps M (2007) Microcirculatory dysfunction in the brain precedes changes in evoked potentials in endotoxininduced sepsis syndrome in rats. Cerebrovasc Dis 23:140-147.

Rosengarten B, Hecht M, Wolff S, Kaps M (2008) Autoregulative function in the brain in an endotoxic rat shock model. Inflamm Res 57:542-546.

Ruiz-Valdepenas L, Martinez-Orgado JA, Benito C, Millan A, Tolon RM, Romero J (2011) Cannabidiol reduces lipopolysaccharideinduced vascular changes and inflammation in the mouse brain: an intravital microscopy study. J Neuroinflammation 8:5.

Salom JB, Torregrosa G, Alborch E (1995) Endothelins and the cerebral circulation. Cerebrovasc Brain Metab Rev 7:131-152.

Sato T, Araki I, Kushikata T, Ohkawa H, Ishihara H, Matsuki A (1995) Decreased hypothalamic prostaglandin D2 and prostaglandin E2 
contents during isoflurane anaesthesia in rats. Can $\mathrm{J}$ Anaesth 42:1031-1034.

Sawamura S, Obara-Nawata M, Takeda K, Hanaoka K (2004) General anesthetics inhibit the nitrous-oxide-induced activation of corticotropin releasing factor containing neurons in rats. Eur $\mathrm{J}$ Pharmacol 503:49-53.

Schmittgen TD, Livak KJ (2008) Analyzing real-time PCR data by the comparative $\mathrm{C}(\mathrm{T})$ method. Nat Protoc 3:1101-1108.

Shimojo N, Jesmin S, Zaedi S, Maeda S, Gando S, Yamaguchi I, Goto K, Miyauchi T (2006) Alterations of gene expressions of preproET-1 and ET receptors in brains of endotoxemic SpragueDawley rats. Exp Biol Med (Maywood) 231:1058-1063.

Shin HK, Jones PB, Garcia-Alloza M, Borrelli L, Greenberg SM, Bacskai BJ, Frosch MP, Hyman BT, Moskowitz MA, Ayata C (2007) Age-dependent cerebrovascular dysfunction in a transgenic mouse model of cerebral amyloid angiopathy. Brain 130:2310-2319.

Sicard K, Shen Q, Brevard ME, Sullivan R, Ferris CF, King JA, Duong TQ (2003) Regional cerebral blood flow and BOLD responses in conscious and anesthetized rats under basal and hypercapnic conditions: implications for functional MRI studies. J Cereb Blood Flow Metab 23:472-481.

Sjakste N, Sjakste J, Boucher JL, Baumane L, Sjakste T, Dzintare M, Meirena D, Sharipova J, Kalvinsh I (2005) Putative role of nitric oxide synthase isoforms in the changes of nitric oxide concentration in rat brain cortex and cerebellum following sevoflurane and isoflurane anaesthesia. Eur J Pharmacol 513:193-205.

Sprung CL, Peduzzi PN, Shatney $\mathrm{CH}$, Schein RM, Wilson MF, Sheagren JN, Hinshaw LB (1990) Impact of encephalopathy on mortality in the sepsis syndrome. The Veterans Administration Systemic Sepsis Cooperative Study Group. Crit Care Med 18:801-806.

Stefanovic B, Bosetti F, Silva AC (2006) Modulatory role of cyclooxygenase-2 in cerebrovascular coupling. Neurolmage 32:23-32.
Tavares E, Minano FJ, Maldonado R, Dascombe MJ (2006) Endotoxin fever in granulocytopenic rats: evidence that brain cyclooxygenase-2 is more important than circulating prostaglandin E(2). J Leukoc Biol 80:1375-1387.

Toda N, Inoue S, Bian K, Okamura T (1988) Endothelium-dependent and independent responses to prostaglandin $\mathrm{H} 2$ and arachidonic acid in isolated dog cerebral arteries. J Pharmacol Exp Ther 244:297-302.

Wahl JR, Goetsch NJ, Young HJ, Van Maanen RJ, Johnson JD, Pea AS, Brittingham A (2005) Murine macrophages produce endothelin-1 after microbial stimulation. Exp Biol Med (Maywood) 230:652-658.

Wilson JX, Young GB (2003) Progress in clinical neurosciences: sepsis-associated encephalopathy: evolving concepts. Can J Neurol Sci 30:98-105.

Wong ML, Bongiorno PB, al-Shekhlee A, Esposito A, Khatri P, Licinio J (1996) IL-1 beta, IL-1 receptor type I and iNOS gene expression in rat brain vasculature and perivascular areas. NeuroReport $7: 2445-2448$.

Wort SJ, Ito M, Chou PC, Mc Master SK, Badiger R, Jazrawi E, de Souza P, Evans TW, Mitchell JA, Pinhu L, Ito K, Adcock IM (2009) Synergistic induction of endothelin-1 by tumor necrosis factor alpha and interferon gamma is due to enhanced NF-kappaB binding and histone acetylation at specific kappaB sites. J Biol Chem 284:24297-24305.

Yamagata K, Matsumura K, Inoue W, Shiraki T, Suzuki K, Yasuda S, Sugiura H, Cao C, Watanabe Y, Kobayashi S (2001) Coexpression of microsomal-type prostaglandin E synthase with cyclooxygenase-2 in brain endothelial cells of rats during endotoxin-induced fever. J Neurosci 21:2669-2677.

Zhao B, Bowden RA, Stavchansky SA, Bowman PD (2001) Human endothelial cell response to gram-negative lipopolysaccharide assessed with cDNA microarrays. Am J Physiol Cell Physiol 281: C1587-C1595. 